СПОСОБ ЛАПАРОСКОПИЧЕСКОГО ДРЕНИРОВАНИЯ ЗАБРЮШИННОЙ КЛЕТЧАТКИ В РАННЕЙ ФАЗЕ ОСТРОГО НЕКРОТИЗИРУЮЩЕГО ПАНКРЕАТИТА 'Белорусец В.Н. (victorbelorusets@yandex.ru),'КарпицкийA.C. (bob@brest.by), ${ }^{2}$ Сегодник B. A. (potolog@brest.by)

'y3 «Брестская областная больница, Брест, Беларусь

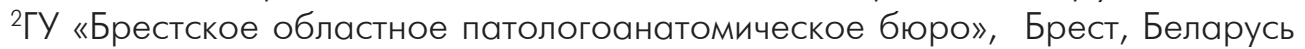

Цель. Выявить закономерности распространения жидкостных образований в парапанкреатической зоне забрюшинного пространства и на основании полученных данных разработать рацииональный способ малоинвазивного дренирования забрюшинной клетчатки для эвакуачии патологического экссудата в ранней фазе острого некротизирующего панкреатита.

Материал и методы. В статье представлены результаты анатомического эксперимента на 69 телах людей, умерших от причин, не связанных с заболеваниями органов брюшной полости и забрюшинного пространства. Изучены пути распространения жидкости, введенной в разные отдель поджелудочной железы, а также эффективность дренирования забрюшинной клетчатки в эксперименте.

Результаты. Наиболее уязвимыми отделами забрюшинной клетчатки при распространении патологической жидкости из зоны поджелудочной железы являются корень брыжейки ободочной кишки, правое и левое околоободочные клетчаточные пространства. Показано, что формирование тоннелей в забрюшинной клетчатке позади углов ободочной кишки является эффективным приемом, значительно улучшающим отток жидкости из парапанкреатической зоны, особенно при левостороннем поражении.

Bblводы. Предложенный способ лапароскопического дренирования забрютинной клетчатки является малоинвазивной патогенетически и анатомически обоснованной дренирующей операцией и может быть применен в раннем лечебном комплексе при остром некротизирующем панкреатите.

Ключевые слова: острый некротизирующий панкреатит, патологический экссудат, забрюшинная клетчатка, анатомический эксперимент, способ лапароскопического дренирования.

\section{Введение}

Лечение пациентов с острым некротизирующим панкреатитом (ОНП) продолжает оставаться одной из нерешенных проблем в неотложной абдоминальной хирургии. Заболеваемость острым панкреатитом (ОП) неуклонно растёт. Постоянно увеличивается удельный вес наиболее тяжелых форм заболевания, достигая 20-25\% $[1,2]$. Несмотря на совершенствование методов диагностики, консервативного лечения, внедрение новых хирургических технологий, летальность при тяжелых формах ОНП за последние десять лет существенно не изменилась и составляет в среднем 20-30\% [3]. ОП лидирует как причина неблагоприятных исходов среди острых абдоминальных заболеваний. В Республике Беларусь за последние годы среди пациентов, умерших от острых хирургических заболеваний органов брюшной полости, пациенты с ОНП составляют более 60\% [1]. Большинство (57-80\%) летальных исходов приходится на пациентов с полиорганной недостаточностью вследствие гнойных осложнений и сепсиса $[4,5]$.

Характерной особенностью ОНП является распространение деструкции на забрюшинную клетчатку (ЗК). Признаки ее поражения обнаруживаются в 84-97\% случаев и рассматриваются многими авторами как неотъемлемый компонент заболевания. Степень вовлечения забрюшинных клетчаточных пространств в деструктивный процесс - важнейший прогностически неблагоприятный фактор [6]. Общепризнанным является факт, что в повреждении ЗК первичным фактором агрессии является ферментативный экссудат. Особенность строения фасциальных структур и клетчаточных пространств позволяет воспалительному экссудату при ОП легко распространяться на связочный аппарат верхнего этажа брюшной полости и корень брыжейки тонкой и поперечно-ободочной кишки. Токсическое действие на кишечную стенку приводит к нарушению всасывания, параличу кишечных ганглиев, в том числе и водителя ритма, к развитию синдрома кишечной недостаточности [7]. Нарушения моторики и микроциркуляции кишечной стенки создают морфологические предпосылки для восходящей колонизации тонкой кишки условно патогенной газообразующей флорой, потери слизистой пищеварительного тракта своей барьерной функции и развития бактериальной кишечной транслокации $[8,9]$. Спектр выделяемых при панкреонекрозе микроорганизмов также свидетельствует в пользу предположения, что микрофлора толстой кишки является основным источником инфицирования девитализированных тканей поджелудочной железы (ПЖ) и окружающей клетчатки [10]. Распространенные формы ферментативного парапанкреатита в 40$70 \%$ случаев эволюционируют в гнойно-некротический парапанкреатит [1, 4].

Таким образом, мероприятия, направленные на удаление ферментативного экссудата из ЗК в максимально ранние сроки, предотвращение его распространения на клетчатку брыжеечных пространств представляются патогенетически обоснованными. Тем не менее, большинство хирургов сдержанно относятся к ранним дренирующим операциям на стадии формирования панкреонекроза, в том числе с применением малоинвазивных технологий $[11,12,13]$. В свя- 
зи с этим рандомизированных исследований, оценивающих эффективность ранних дренирующих малоинвазивных операций, в настоящее время не существует. Проведение исследований в этом направлении представляется весьма перспективным.

Цель - выявить закономерности распространения жидкостных образований в парапанкреатической зоне забрюшинного пространства и на основании полученных данных разработать рациональный способ малоинвазивного дренирования ЗК для эвакуации патологического экссудата в ранней фазе ОНП.

\section{Материал и методы}

Объектом изучения послужили 69 тел людей, умерших от причин, не связанных с заболеваниями органов брюшной полости и забрюшинного пространства. Исследование проведено с соблюдением принципов биомедицинской этики в обращении с телами умерших, одобрено комитетом по этике Брестской областной больницы (протокол № 1 от 09.01.2015 г.), комитетом по биомедицинской этике Гродненского государственного медицинского университета (протокол № 2 от 06.01.2015 г.).

Работа проводилась в 2 этапа. На первом этапе были изучены пути распространения жидкости, введенной в разные отделы ПЖ. Эта часть исследования выполнена на 45 телах, из которых мужчин было 29, женщин - 16. Средний возраст 67 [58-76] лет (от 35 до 86 лет). В анатомическом эксперименте использован широко применяемый в топографической анатомии метод инъецирования фасциально-клетчаточных пространств окрашенными растворами. Моделирование распространения жидкости в ЗК проводилось путем введения окрашенного раствора в разные отделы ПЖ с учетом особенностей строения ее фасциального футляра. Брюшинно-фасциальный футляр тела и хвоста замкнут и изолирован от фасциального футляра головки. После лапаротомии и рассечения желудочно-ободочной связки иглой d 1мм пунктировалась ПЖ на глубину 1 см в области головки в 21 случае и на границе тела и хвоста - в 24 случаях. С помощью системы для непрерывной подачи жидкости в ткань ПЖ под давлением 120-150 мм рт. ст. вводился физиологический раствор хлорида натрия, окрашенный метиленовым синим в $0,02 \%$ концентрации (к 250 мл физиологического раствора хлорида натрия добавлено 5 мл 1\% раствора метиленового синего). Экспозиция раствора 30 минут. Объем вводимого раствора - 250 мл. Исследованиями Кузнецова Н. А., Поповой Е. Ю. доказано, что объем от 100 до 280 мл позволял гарантированно разрушить фасциальный футляр ПЖ, в то же время предотвратить механический разрыв фасций забрюшинного пространства [14].

Результат оценивался при визуальном осмотре путем препарирования клетчаточных слоев забрюшинного пространства до и после извлечения органокомплекса.

Второй этап работы выполнен на 24 телах, из которых случайным образом сформированы
4 экспериментальные группы. Мужчин было 14, женщин - 10. Средний возраст составил 66 [56,581] лет (от 36 до 88). Эта часть исследования предпринята нами с целью поиска оптимального способа дренирования парапанкреатической зоны забрюшинного пространства и заключалась в следующем. После лапаротомии производилось рассечение париетальной брюшины в области переходной складки на расстоянии $1 \mathrm{~cm}$ кнаружи от печеночного угла ободочной кишки (первая группа - 5 наблюдений) и селезеночного угла ободочной кишки (третья группа -5 наблюдений) без проникновения в ЗК. Через аналогичные разрезы брюшины формировались тоннели в ЗК позади печеночного и селезеночного углов толстой кишки протяженностью 5-6 см по направлению к головке ПЖ справа (вторая группа - 7 наблюдений) и к хвосту ПЖ слева (четвертая группа - 7 наблюдений). Пересекалась желудочно-ободочная связка, обнажалась ПЖ. В ткань ПЖ в области головки (первая и вторая группы) и хвоста (третья и четвертая группы) под давлением 120-150 мм рт. ст. вводилось фиксированное количество (250 мл) окрашенного раствора. Измерялось количество раствора, выделившегося в боковые каналы брюшной полости через выполненные предварительно разрезы брюшины или сформированные тоннели в ЗК.

Учитывая малую численность выборок в группах, применены методы непараметрической статистики. Данные представлены в виде Ме [25\%; 75\%], где Ме - медиана, [25\%; 75\%] - 25-я и 75-я процентили. Для оценки достоверности различий независимых выборок использовали непараметрический критерий Манна-Уитни (U). Критическое значение уровня значимости при проверке статистических гипотез принимали равным 5\% $(\mathrm{p}<0,05)$.

\section{Результаты и обсуждение}

Из приведенных в таблице 1 данных следует, что из левых отделов ПЖ жидкость свободно проникала в корень брыжейки поперечно-ободочной кишки $(95,8 \%)$, левое околоободочное пространство $(91,7 \%)$, а также в клетчатку желудочно-селезеночной и поджелудочно-селезеночной связок $(66,7 \%)$. В значительном количестве случаев раствор достигал диафрагмы, пропитывая левую желудочно-диафрагмальную связку $(29,2 \%)$ и распространялся на клетчатку малого сальника $(29,2 \%)$.

Из головки ПЖ жидкость беспрепятственно распространяется на клетчатку малого сальника $(76,2 \%)$ и корня брыжейки поперечно-ободочной кишки $(95,2 \%)$. В значительном количестве наблюдений отмечено поступление раствора в правое околоободочное пространство в области печеночного изгиба ободочной кишки $(57,1 \%)$, в корень брыжейки тонкой кишки $(47,6 \%)$ и печеночно-двенадцатиперстную связку $(47,6 \%)$.

В то же время проникновение раствора в паранефральные пространства, а также в собственно забрюшинное клетчаточное пространство отмечено лишь в единичных случаях. Характерно, что прокрашивание брыжейки тонкой кишки 
Tаблица 1. - Частота распространения раствора из поджелудочной железы в клетчаточные зоны и слои забрюшинного пространства, $\mathrm{n}(\%)$

\begin{tabular}{|l|c|c|}
\hline \multirow{2}{*}{\multicolumn{1}{|c|}{ Области распространения }} & \multicolumn{2}{|c|}{ Отделы поджелудочной железы } \\
\cline { 2 - 3 } & $\begin{array}{c}\text { Головка } \\
\mathrm{n}(\%)\end{array}$ & $\begin{array}{c}\text { Тело и хвост } \\
\mathrm{n}(\%)\end{array}$ \\
\hline Малый сальник & $16(76,2 \%)$ & $7(29,2 \%)$ \\
\hline Желудочно-селезеночная связка & $1(4,8 \%)$ & $16(66,7)$ \\
\hline Желудочно-диафрагмальная связка & - & $7(29,2 \%)$ \\
\hline $\begin{array}{l}\text { Печеночно-двенадцатиперстная } \\
\text { связка }\end{array}$ & $10(47,6 \%)$ & - \\
\hline $\begin{array}{l}\text { Брыжейка поперечно-ободочной } \\
\text { кишки }\end{array}$ & $20(95,2 \%)$ & $23(95,8 \%)$ \\
\hline Брыжейка тонкой кишки & $10(47,6 \%)$ & $1(4,2 \%)$ \\
\hline $\begin{array}{l}\text { Правое околоободочне } \\
\text { пространство }\end{array}$ & $12(57,1 \%)$ & - \\
\hline $\begin{array}{l}\text { Левое околоободочное } \\
\text { пространство }\end{array}$ & - & $22(91,7 \%)$ \\
\hline Левое околопочечное пространство & - & \\
\hline $\begin{array}{l}\text { Правое околопочечное } \\
\text { пространство }\end{array}$ & $2(9,5 \%)$ & - \\
\hline $\begin{array}{l}\text { Собственно забрюшинное } \\
\text { пространство }\end{array}$ & - & \\
\hline
\end{tabular}

полость выделилось более четверти введенного в ткань ПЖ раствора $(26,2 \%)$, в некоторых наблюдениях более $50 \%$.

Через разрезы брюшины и сформированные тоннели в ЗК справа окрашенный раствор выделялся в правый боковой канал в небольшом количестве (не более 9,6\%) в половине случаев. Существенных различий в количестве выделившегося в брюшную полость раствора при формировании тоннеля, по сравнению с рассечением брюшины, не отмечалось $(\mathrm{p}>0,05)$.

На основании полученных данных можно констатировать, что основная барьерная функция при воспалительных процессах в зоне ПЖ принадлежит забрюшинной фасции, препятствующей распространению жидкости на паранефральное и собственно забрюшинное пространства.

Позадибрыжеечная фас-

происходит при введении жидкости в область головки ПЖ, а распространение раствора на область ворот селезенки и в поддиафрагмальное пространство - при введении красящего раствора в область тела и хвоста.

Приведенные в таблице 2 данные показывают, что из разрезов брюшины левого бокового канала отмечено выделение окрашенного раствора в трех наблюдениях (40\%) в количестве 10-35 мл или 4-14\% от введенного объема. Через сформированные тоннели в ЗК слева в брюшную ция поперечно-ободочной кишки не является препятствием для распространения жидкости из поражении головки ПЖ, так и левых её отделов.

Описываемые многими авторами правое и левое околоободочные пространства как замкнутые фасциально-клетчаточные образования, в полной мере таковыми не являются, так как введенный в ПЖ раствор свободно проникал в них. По нашим данным, в 91,7\% случаев слева и в $51,7 \%$ случаев справа. зоны ПЖ на клетчатку корня брыжейки как при

Tаблица 2. - Количество выделившегося раствора из забрюшинной клетчатки в брюшную полость, мл $(\%)$

\begin{tabular}{|c|c|c|c|c|c|c|c|}
\hline \multicolumn{8}{|c|}{ Отделы поджелудочной железы } \\
\hline \multicolumn{4}{|c|}{ Головка } & \multicolumn{4}{|c|}{ Тело и хвост } \\
\hline \multicolumn{2}{|c|}{$\begin{array}{c}1 \text { группа } \\
\text { Рассечение брюшины n-5 }\end{array}$} & \multicolumn{2}{|c|}{$\begin{array}{c}2 \text { группа } \\
\text { Формирование тоннеля n-7 }\end{array}$} & \multicolumn{2}{|c|}{$\begin{array}{c}3 \text { группа } \\
\text { Рассечение брюшины n-5 }\end{array}$} & \multicolumn{2}{|c|}{$\begin{array}{c}4 \text { группа } \\
\text { Формирование тоннеля n-7 }\end{array}$} \\
\hline $\begin{array}{l}\text { Введено } \\
\text { мл }\end{array}$ & $\begin{array}{c}\text { Выделилось } \\
\text { мл (\%) }\end{array}$ & $\begin{array}{c}\text { Введено } \\
\text { мл }\end{array}$ & $\begin{array}{l}\text { Выделилось } \\
\text { мл (\%) }\end{array}$ & $\begin{array}{c}\text { Введено } \\
\text { мл }\end{array}$ & $\begin{array}{c}\text { Выделилось } \\
\text { мл (\%) }\end{array}$ & $\begin{array}{c}\text { Введено } \\
\text { мл }\end{array}$ & $\begin{array}{l}\text { Выделилось } \\
\text { мл (\%) }\end{array}$ \\
\hline \multirow{7}{*}{250} & $12(4,8 \%)$ & \multirow{7}{*}{250} & $0(0 \%)$ & \multirow{7}{*}{250} & $10(4 \%)$ & \multirow{7}{*}{250} & $120(48 \%)$ \\
\hline & $0(0 \%)$ & & $0(0 \%)$ & & $35(14 \%)$ & & $85(34 \%)$ \\
\hline & $10(4 \%)$ & & $0(0 \%)$ & & $17(6,8 \%)$ & & $48(19,2 \%)$ \\
\hline & $0(0 \%)$ & & $17(6,8 \%)$ & & $0(0 \%)$ & & $135(54 \%)$ \\
\hline & $16(6,4 \%)$ & & $18(7,2 \%)$ & & $0(0 \%)$ & & $0(0 \%)$ \\
\hline & - & & $24(9,6 \%)$ & & - & & $50(20 \%)$ \\
\hline & - & & $0(0 \%)$ & & - & & $20(8 \%)$ \\
\hline $\begin{array}{c}\mathrm{Me}[25 ; 75] \\
\text { мл }(\%)\end{array}$ & $\begin{array}{c}10,0 \\
{[0-12,0]} \\
(2,2 \%)\end{array}$ & & $\begin{array}{c}10,0 \\
{[0-17,0]} \\
(3,4 \%)\end{array}$ & & $\begin{array}{c}14,0 \\
{[0-17,0]} \\
(6,3 \%)\end{array}$ & & $\begin{array}{c}50,0 \\
{[20,0-85,0]} \\
(26,2 \%)\end{array}$ \\
\hline \multicolumn{8}{|c|}{ Mann-Whitney U-Test (p) } \\
\hline \multicolumn{4}{|c|}{$\mathrm{p} 1-2>0,05$} & \multicolumn{4}{|c|}{ p3-4<0,05 } \\
\hline
\end{tabular}


Рассечение париетальной брюшины боковых каналов не обеспечивает достаточных условий для эвакуации экссудата из парапанкреатической клетчатки. Формирование тоннелей в ЗК позади углов ободочной кишки значительно улучшает отток жидкости из парапанкреатической зоны при левостороннем поражении $(\mathrm{p}<0,05)$, уменьшает пропитывание красящим раствором других отделов ЗК.

В ходе анатомического эксперимента не получено данных, свидетельствующих об улучшении оттока экссудата из зоны головки ПЖ при формировании тоннеля позади печеночного угла ободочной кишки $(\mathrm{p}>0,05)$. Такой результат имеет топографо-анатомическое объяснение. Фасциальный футляр головки ПЖ дополняется по наружной поверхности 12-перстной кишкой, имеющей собственный фасциальный футляр, а также супрамезоколической фасцией ПЖ и субмезоколической предуоденальной фасцией Фреде [15]. По данным Поповой Е. Ю. (2004 г.), проникновение раствора в правое околоободочное пространство происходит опосредованно через корень брыжейки поперечно-ободочной кишки после прорыва через фасцию корня брыжейки толстой кишки [16].

Наиболее рациональными зонами для дренирования ЗК при панкреонекрозе, на наш взгляд, являются правое и левое околоободочные клетчаточные пространства (частота поражаемости, простота и безопасность хирургического доступа, непосредственная близость к источнику экссудации).

Принципиально важным этапом считаем формирование тоннелей в ЗК позади углов ободочной кишки. Эта манипуляция позволяет разрушить позадиободочную фасцию восходящей и нисходящей ободочной кишки (фасция Тольдта), создать благоприятные условия для оттока ферментативного экссудата в желаемом направлении и предупредить его распространение на другие отделы забрюшинного пространства, прежде всего на клетчатку брыжейки поперечно-ободочной кишки.

Основываясь на полученных экспериментальных данных, нами предложен способ лапароскопического дренирования ЗК при некротизирующем панкреатите в стадии стерильного панкреонекроза (Патент РБ на изобретение № 21055 от 09.02.2017 г.). Данный лечебный прием использован нами в рамках клинического исследования в соответствии с принципами Хельсинкской декларации, надлежащей клинической практики (GCP), одобрен комитетом по этике Брестской областной больницы (протокол № 1 от 09.01.2015 г.), комитетом по биомедицинской этике Гродненского государственного медицинского университета (протокол № 2 от 06.01.2015 г.). От всех пациентов получено информированное согласие на применение данного вида хирургического вмешательства.

При выполнении лапароскопии в положении пациента на боку осуществляли рассечение париетальной брюшины в области переходных складок углов ободочной кишки и формировали в ЗК тоннели протяжённостью 5-6 см позади селезеночного угла ободочной кишки по направлению к хвосту поджелудочной железы слева и позади печёночного угла ободочной кишки справа (рисунок). Затем через лапароскопические порты в подвздошных областях живота в сформированные тоннели устанавливали дренажные трубки, укладывая их в боковые каналы брюшной полости. При необходимости производилось дополнительное рассечение заднего листка париетальной брюшины кнаружи от ободочной кишки в зоне максимального скопления экссудата. Отверстия в дренажных трубках для удаления экссудата предусматривались в забрюшинной и в интраабдоминальной части.

Такое расположение дренажных трубок позволило обеспечить длительное адекватное дренирование ЗК, а также способствовало удалению выпота из брюшной полости.

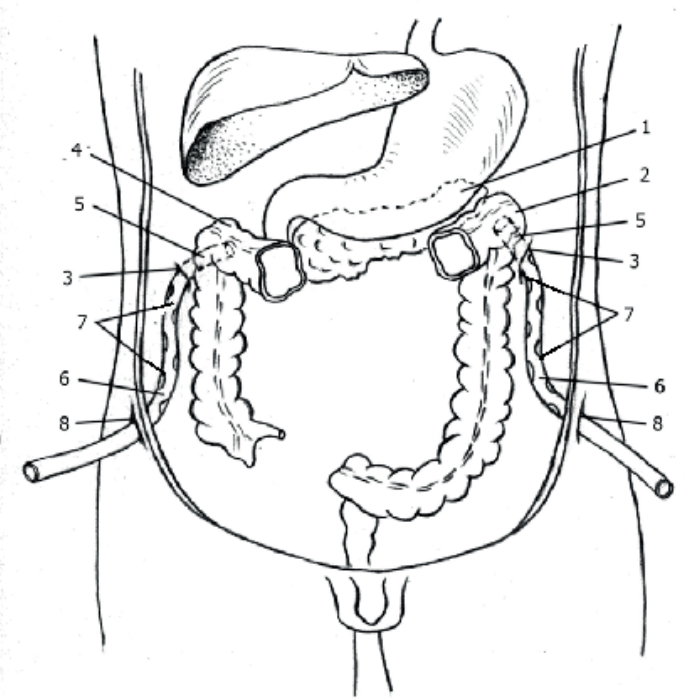

1 - поджелудочная железа; 2 - селезеночный угол ободочной кишки; 3 - разрезы париетальной брюшины в области селезёночного и печёночного угла ободочной кишки; 4 - печеночный угол ободочной кишки; 5 - забрюшинная часть дренажа; 6 - интраабдоминальная часть дренажа; 7 - дополнительные дренажные отверстия в трубках по ходу боковых каналов; 8 -места входа дренажей в брюшную полость

Рисунок. - Способ видеолапароскопического дренирования забрюшинной клетчатки при остром некротизирующем панкреатите в стадии стерильного панкреонекроза

В ходе анатомического эксперимента при введении в ткань поджелудочной железы фиксированного количества (250 мл) окрашенного раствора и формировании тоннеля позади печеночного угла ободочной кишки не получено данных, свидетельствующих об улучшении оттока экссудата из зоны головки ПЖ. Тем не менее, считаем целесообразным при ОП применение предлагаемого способа дренирования при правостороннем поражении. Клиническое применение показало, что лапароскопическое дренирование ЗК предложенным способом при ло- 
кализации патологического процесса в области головки ПЖ является эффективным приемом для эвакуации значительных объемов патологического экссудата.

Описанный трансабдоминальный лапароскопический доступ к ЗК выполняется с учетом топографии забрюшинного пространства без вскрытия фасциально-клетчаточных пространств, не подвергшихся ферментативной агрессии, с минимальным разрушением анатомо-физиологических барьеров вокруг патологических очагов. Указанный доступ является наиболее безопасным в плане возможных ятрогенных осложнений, не требует дополнительных инструментов, специальной подготовки хирурга и может выполняться в любом хирургическом стационаре, оснащенном лапароскопическим оборудованием.

При наличии показаний лапароскопический метод позволяет одновременно выполнить дренирование сальниковой сумки, холецистостомию.

\section{Bblводы}

1. Наиболее уязвимым клетчаточным пространством при распространении патологической жидкости из зоны поджелудочной железы является корень брыжейки ободочной кишки. Прорыв экссудата через позадибрыжеечную фасцию поперечно-ободочной кишки происходит более чем в 95\% случаев как при поражении головки поджелудочной железы, так и левых её отделов.

2. Формирование тоннелей в забрюшинной клетчатке позади углов ободочной кишки позволяет путем дополнительного разрушения фасции Тольдта создать благоприятные условия для оттока ферментативного экссудата, в значительной степени предупредить его распространение на другие отделы забрюшинного пространства, прежде всего на клетчатку корня брыжейки поперечно-ободочной кишки. Таким образом, уменьшается объем поражения забрюшинной клетчатки, а также снижается вероятность бактериальной кишечной транслокации и инфицирования панкреонекроза.

3. Лапароскопическое дренирование забрюшинной клетчатки по предложенной методике является малоинвазивной, патогенетически и анатомически обоснованной дренирующей операцией, и может быть применено в раннем лечебном комплексе при остром некротизирующем панкреатите.

\section{Литература}

1. Шорох, Г. П. Острый деструктивный панкреатит / Г. П. Шорох, С. Г. Шорох. - Минск : Парадокс, 2013. - 208 с.

2. Yadav, D. The epidemiology of pancreatitis and pancreatic cancer / D. Yadav, A. B. Lowenfel // Gastroenterology. 2013. - Vol. 144, № 6. - P. 1252-1261. - doi: 10.1053/j. gastro.2013.01.068

3. Prognostic markers in acute pancreatitis / I. P. Gomatos [et al.] // Expert Rev. Mol. Diagn. - 2014. - Vol. 14, № 3. P. 333-346. - doi: 10.1586/14737159.2014.897608.

4. Хирургическая тактика при остром некротизирующем панкреатите / П. Г. Кондратенко [и др.] // Украинский журнал хирургии. - 2013. - Т. 22, № 3. - С. 150-155.

5. Мультивариантный анализ факторов, ассоциированных с непосредственными причинами смерти при тяжелом остром панкреатите / О. А. Куделич [и др.] // Новости Хирургии. - 2014. - Т. 22, № 4. - С. 417-427. - doi: 10.18484/2305-0047.2015.4.385.

6. Майоров, В. М. Морфологические закономерности поражения и распространения деструктивного процесса в забрюшинном пространстве при тяжелом остром некротизирующем панкреатите по данным аутопсии / В. М. Майоров, 3. А. Дундаров, Ю. Н. Авижец // Новости хирургии. - 2015. - Т. 23, № 4. - С. 385-390. - doi: 10.18484/2305-0047.2015.4.385.

7. Диагностика и лечение синдрома кишечной недостаточности у больных с острым панкреатитом (обзор) [Электронный ресурс] / И. Н. Климович [и др.] // Современные проблемы науки и образования. - 2014. № 5. - Режим доступа: http://www.science-education.ru/ru/ article/view?id=15013. - Дата доступа: 26.02.2018.

8. Alterations in intestinal permeability and endotoxemia in severe acute pancreatitis / M. Sharma [et al.] // Trop. Gastroenterol. - 2012. - T. 33, № 1. - P. 45-50.

9. The intestinal mucus layer is a critical component of the gut barrier that is damaged during acute pancreatitis /
J. E. Fishman [et al.] // Shock. - 2014. - Vol. 42, № 3. - P. 264270. - doi:10.1097/SHK.0000000000000209.

10. Андрющенко, Д. В. Острый панкреатит: приоритетные составляющие комплексного хирургического лечения с позиций современных научных знаний / Д. В. Андрющенко, В. А. Маглёванный, В. П. Андрющенко // Хирургия. Восточная Европа. - 2013. - № 2 (06). - С. 120 126.

11. Necrotizing Pancreatitis: Diagnosis, Imaging, and Intervention / J. Y. Shyu [et al.] // RadioGraphics. - 2014. Vol. 34, № 5. - P. 1218-1239.

12. Management of Acute Pancreatitis / S. Tenner [et al.] // Am J. Gastroenterol. - 2013. - № 108. - P. 1400-1415. doi:10.1038/ajg.2013.218.

13. IAP/APA evidence-based guidelines for the management of acute pancreatitis / Working Group IAP/APA Acute Pancreatitis Guidelines // Pancreatology. - 2013. - Vol. 13, № 4. - P. 1-15.

14. Распространение патологического процесса в забрюшинном пространстве при некротическом панкреатите / Н. А. Кузнецов [и др.] // Хирургия. - 2004. - № 2. C. 11-16.

15. Хирургическая анатомия поджелудочной железы / В. М. Копчак [и др.]. - Киев : Аскания, 2011. - 141 с.

16. Попова, Е. Ю. Прогнозирование путей распространения патологического процесса в забрюшинном пространстве у больных панкреонекрозом (экспериментально-клиническое исследование) : дис. ... канд. мед. наук : 14.00.27; 14.00.02 / Е. Ю. Попова. - Москва, 2004. - 147 с.

\section{References}

1. Shoroh GP, Shoroh SG. Ostryj destruktivnyj pankreatit [Acute destructive pancreatitis]. Minsk: Paradoks; 2013. 208 p. (Russian).

2. Yadav D, Lowenfel AB. The epidemiology of pancreatitis and pancreatic cancer. Gastroenterology. 2013;144(6):1252- 
1261. doi: 10.1053/j.gastro.2013.01.068.

3. Gomatos IP, Xiaodong X, Ghaneh P, Halloran C, Raraty M, Lane B, Sutton R, Neoptolemos JP. Prognostic markers in acute pancreatitis. Expert Rev. Mol. Diagn. 2014;14(3):333-346. doi: 10.1586/14737159.2014.897608.

4. Kondratenko PG, Konkova MV, Vasilev AA, Epifancev AA, Dzhansyz IN, Shirshov IV, Judin AA. Hirurgicheskaja taktika pri ostrom nekrotizirujushhem pankreatite [Surgical tactics in acute necrotizing pancreatitis]. Ukrainskij zhurnal hirurgii [Ukrainian Journal of Surgery]. 2013;3(22):150-55. (Russian).

5. Kudelich OA, Kondratenko GG, Judina OA, Motoljanec PM. Multivariantnyj analiz faktorov, associirovannyh s neposredstvennymi prichinami smerti pri tjazhelom ostrom pankreatite [Multivariate analysis of factors associated with immediate causes of death in severe acute pancreatitis] Novosti Hirurgii [Surgery News]. 2014;22(4):417-427. doi: 10.18484/2305-0047.2014.4.416. (Russian).

6. Majorov VM, Dundarov ZA, Avizhec JuN Morfologicheskie zakonomernosti porazhenija i rasprostranenija destruktivnogo processa $\mathrm{v}$ zabrjushinnom prostranstve pri tjazhelom ostrom nekrotizirujushhem pankreatite po dannym autopsii [Morphological regularities of the defeat and spread of the destructive process in the retroperitoneal space with severe acute necrotizing pancreatitis according to autopsy data] Novosti Hirurgii [Surgery News]. 2015;23(4):385-90. doi: 10.18484/2305-0047.2015.4.385. (Russian).

7. Klimovich IN, Maskin SS, Levchenko SA, Zemljakov DS, Aleksandrov VV. Diagnostika i lechenie sindroma kishechnoj nedostatochnosti u bolnyh s ostrym pankreatitom (obzor) [Internet]. Sovremennye problemy nauki i obrazovanija [Modern problems of science and education]. 2014;5. Available from: http://www.science-education.ru/ru/article/ view?id=15013. (Russian).

8. Sharma M, Sachdev V, Singh N, Bhardwaj P, Pal A, Kapur S, Saraya A. Alterations in intestinal permeability and endotoxemia in severe acute pancreatitis. Trop. Gastroenterol. 2012;33(1):45-50.

9. Fishman JE, Levy G, Alli V, Zheng X, Mole DJ, Deitch EA. The intestinal mucus layer is a critical component of the gut barrier that is damaged during acute pancreatitis. Shock. 2014;42(3):264-270. doi: 10.1097/SHK.0000000000000209.

10. Andrjushhenko DV, Magljovannyj VA, Andrjushenko VP. Ostryj pankreatit: prioritetnye sostavljajushhie kompleksnogo hirurgicheskogo lechenija s pozicij sovremennyh nauchnyh znanij [Acute pancreatitis: priority components of complex surgical treatment from the standpoint of modern scientific knowledge]. Hirurgija. Vostochnaja Evropa [Surgery. Eastern Europe]. 2013;2(06):120126. (Russian).

11. Shyu JY, Sainani NI, Sahni VA, Chick JF, Chauhan NR, Conwell DL, Clancy TE, Banks PA, Silverman SG. Necrotizing pancreatitis: diagnosis, imaging, and intervention. Radiographics. 2014;34(5):1218-39. doi: 10.1148/ rg.345130012.

12. Tenner S, Baillie J, DeWitt J, Vege SS. Management of Acute Pancreatitis. Am J. Gastroenterol. 2013;108:14001415. doi:10.1038/ajg.2013.218.

13. Working Group IAP/APA Acute Pancreatitis Guidelines. IAP/APA evidence-based guidelines for the management of acute pancreatitis. Pancreatology. 2013;13(4):115. doi: 10.1016/j.pan.2013.07.063.

14. Kuznecov NA, Rodoman GV, Brontvejn AT, Shalaeva TI, Popova EJu. Rasprostranenie patologicheskogo processa $\mathrm{v}$ zabrjushinnom prostranstve pri nekroticheskom pankreatite [The spread of the pathological process in the retroperitoneal space with necrotic pancreatitis]. Hirurgija [Surgery]. 2004;2:11-16. (Russian).

15. Kopchak VM, Usenko AJu, Kopchak KV, Zelinskij AI. Hirurgicheskaja anatomija podzheludochnoj zhelezy [Surgical anatomy of the pancreas]. Kiev: Askanija; 2011. 141 p. (Russian).

16. Popova EJu. Prognozirovanie putej rasprostranenija patologicheskogo processa $\mathrm{v}$ zabrjushinnom prostranstve $\mathrm{u}$ bolnyh pankreonekrozom (jeksperimental'no-klinicheskoe issledovanie) [Prediction of the pathways of the pathological process in the retroperitoneal space in patients with pancreatonecrosis (experimental and clinical study)] [masters thesis]. Moscow (Russia): Russian State Medical University; 2004. 147 p. (Russian).

\title{
METHOD OF LAPAROSCOPIC DRAINAGE OF RETROPERITONEAL FAT TISSUE IN EARLY PHASE OF ACUTE NECROTIZING PANCREATITIS
}

\author{
'Belorusets V. N., 'Karpitski A. S., ${ }^{2}$ Siahodnik V. A.
}

'Healthcare Institution "Brest Regional Hospital", Brest, Belarus

${ }^{2}$ State Institution "Brest Regional Pathoanatomical Bureau", Brest, Belarus

Objective. To reveal the regularities of liquid formations distribution in the parapancreatic zone of retroperitoneum and on the basis of the obtained data to develop a rational method of minimally invasive drainage of retroperitoneal fat tissue for the evacuation of pathological exudate in the early phase of acute necrotizing pancreatitis.

Material and methods. The article presents the results of an anatomical experiment on 69 bodies of people who died from causes other than abdominal cavity and retroperitoneum diseases. We studied the ways of distribution of the fluid injected into various parts of the pancreas, as well as the effectiveness of retroperitoneal fat tissue drainage during the experiment.

Results. The most vulnerable parts of retroperitoneal fat tissue during the distribution of pathological liquid from the pancreas are the root of mesentery, as well as the right and left paracolic gutters. It has been shown that the formation of tunnels in the retroperitoneal fat tissue behind the colonic flexures is an effective method that significantly improves the efflux of fluid from the parapancreatic zone, especially in left-sided lesions.

Conclusions. The proposed method of laparoscopic drainage of retroperitoneal fat tissue is a minimally invasive drainage surgery, which is pathogenetically and anatomically substantiated and can be used as a part of early treatment of acute necrotizing pancreatitis.

Keywords: acute necrotizing pancreatitis, pathological exudate, retroperitoneal fat tissue, anatomical experiment, laparoscopic drainage method.

Поступила: 27.02.2018

Отреиензирована: 28.03 .2018 